\title{
Can the COVID-19 pandemic and oil prices drive the US Partisan Conflict Index?
}

\author{
Emmanuel Apergis', Nicholas Apergis ${ }^{2}$ (1) \\ ${ }^{1}$ Business Administration, University of Huddersfield, UK, ${ }^{2}$ Economics and Finance, University of Derby, UK \\ Keywords: conflict index, us partisan, oil prices, covid-19 \\ https://doi.org/10.46557/001c.13144
}

\section{Energy RESEARCH LETTERS}

Vol. 1, Issue 1, 2020

This paper investigates the effect of the COVID-19 and oil prices on the US partisan conflict. Using daily data on world COVID-19 and oil prices, monthly data on the US Partisan Conflict index, and the MIDAS method, the finding suggests that both COVID-19 and oil prices mitigate US political polarization. The finding implies that political leaders aim low for partisan gains during stressful times.

\section{INTRODUCTION}

There is abundant evidence suggesting a substantial increase in polarisation across political parties in the US (Boxell et al., 2017). Furthermore, there is a growing debate on whether voters view the economy through a 'partisan perceptual screen', i.e. whether their assessment and interpretation of economic conditions depend on whether the White House is occupied by the party they support (McGrath, 2017). Partisan conflict has been a dominant issue in US politics over recent years. Republicans and Democrats disagree on the role of government in various social issues. These political conflicts have real and sometimes highly visible consequences, such as seen in the clash over budget negotiations and the debt ceiling crises over the US government shutdowns in 2013, 2018 and 2019, which had adverse effects on investment decisions.

The rise in partisan conflict has been widely discussed in the literature (Layman et al., 2006; McCarty et al., 2006) because partisan conflict has substantive policy consequences, associated with increased levels of political gridlock (Jones, 2001), implying reduced rates of policy innovation and a decreased ability to adapt to changes in economic, social, or demographic circumstances(Gupta et al., 2019; McCarty, 2007).

Moreover, the world has experienced a new global crisis, associated with the outbreak of the COVID-19 pandemic. This pandemic has caused the death of over 200,000 people (at the time of writing this paper) around the globe, with the majority of deaths concentrated in Europe and the US. The impact of COVID-19 does not only cause increasing fatality ratios, but it also generates negative spillovers to the financial and real economic systems. Despite the prompt and massive responses of both monetary and fiscal authorities, the impact on the real economy is expected to be worse in comparison to the global financial crisis and the economic depressions of the past. The world also, simultaneous to COVID-19, experienced an oil crisis when Saudi Arabia decided to flood the market with oil. The result was a dramatic fall in oil prices in March 2020 when negative prices were recorded in certain futures contracts.

The goal of this study is to explore, for the first time, how COVID-19 and oil price events occurred over the period January 2020-April 2020 to drive the US Partisan Conflict Index (PCI). The literature has focused on exploring the association between oil prices and volatility and economic policy uncertainty (Aloui et al., 2016; Uddin et al., 2018), but no study has considered the role of partisan conflict linked to oil prices and volatility.

It is expected that despite the increased polarization in the US political system, major events, such as the on-going COVID-19 pandemic, as well as the recent abnormal oil market crisis, may recede this polarization. In other words, the US political system has realized that the COVID-19 outbreak, as well as the oil market crisis, is seriously threatening physical and economic life in the US. These crises pose a major threat to the national economy and public health. Republicans and Democrats seem to share similar views on certain aspects of the COVID-19 outbreak. To this end, the analysis makes use of the proposed PCI, constructed by Azzimonti (2018), to track the link between this index, COVID-19, and oil prices. The paper contributes to the literature by filling the gap in terms of the effect of oil and pandemic crises on the US PCI.

Section 2 describes the methodology employed, while Section 3 provides data description and definitions, along with selected descriptive statistics. Section 4 presents the empirical results. The final section concludes.

\section{METHODOLOGY}

Given that we need to combine the estimation of high frequency data, i.e. daily oil prices and COVID-19 cases with lower frequency data, i.e. monthly PCI, the analysis makes use of the Mixed Data Sampling (MIDAS) model proposed by Ghysels et al. (2004, 2007). The MIDAS regression enables the analysis to associate variables with different frequencies by reducing the number of parameters to estimate; this can be achieved by using weighting functions with only a few hyper-parameters, such as the distributed lag polynomials. The MIDAS regression relies on a flexible aggregation function with minimal restrictions, allowing a data-generated weighting scheme (Andreou et al., 2010). The basic MIDAS model is given by:

$$
\begin{aligned}
\mathrm{PCI}_{t}= & a+b_{1} B\left(L^{\frac{1}{m}} ; \theta_{1}\right) \text { COVID }-19_{t} \\
& +\rho \mathrm{PCI}_{t-1}+b_{2} B\left(L^{\frac{1}{m}} ; \theta_{1}\right) \mathrm{oil}_{t} \\
& +b_{1} B\left(L^{\frac{1}{m}} ; \theta_{1}\right) \text { COVID }-19_{t}+\varepsilon_{t}
\end{aligned}
$$

where $L$ denotes a lag specification and $\varepsilon$ is the error term. The model specification in Equation (1) is in the class of 
Table 1. Descriptive statistics

\begin{tabular}{lcccc}
\hline Variables & Mean & SD & Min & Max \\
\hline Oil prices (WTI)(\$ bb) & 33.9 & 17.6 & -37 & 58.3 \\
Oil prices (Brent)(\$ bb) & 37.9 & 17.9 & 9.1 & 63.7 \\
US partisan conflict index & 97 & 58.8 & 34.8 & 151 \\
COVID-19(\# of incidences) & $745,986.90$ & $979,284.00$ & $4,579.00$ & $3,191,465.00$ \\
COVID-19(\# of deaths) & $46,520.01$ & $68,328.60$ & 106 & $226,882.00$
\end{tabular}

This table reports selected basic descriptive statistics of the main oil price variables (WTI and Brent), US Partisan conflict index (PCI), and COVID-19 incidences and deaths. Each variables' mean, standard deviation (SD), minimum (Min.) and maximum (Max.) are reported.

ADL-MIDAS regressions introduced by Andreou et al. (2013), offering the structure of the ADL (Augmented Distribution Lag) regression with mixed frequency data. This type of modelling specifications offers flexibility in combining data coming from different frequencies. The variable of PCI enters Equation (1) with a lag to capture potential persistence of the US partisan conflict environment. Moreover, the higher the lagged coefficient is, the more it may help explain part of the slow recovery of the partisan conflict environment following the pandemic effect. In other words, this persistence variable captures the role of COVID-19 pandemic shock in potentially rising levels of polarization. The functions:

$$
B\left(L^{\frac{1}{m}} ; \theta\right)=\sum_{k=1}^{K} b(k ; \theta) L^{\frac{k}{m}}
$$

selects the weighting scheme for high-frequency data, where $\quad L^{\frac{k}{m}}$ COVID $-19_{t-1}=$ COVID $-19_{t-1-\frac{k}{m}} \quad$ and $L^{\frac{k}{m}}$ oil $_{t-1}=$ oil $_{t-1-\frac{k}{m}}$. K denotes the number of the lagged high frequency drivers, and $m$ is the number of days in a month. Although the literature offers various diverse functional forms of MIDAS polynomial weights, aimed at achieving parsimony, the analysis here makes use of the normalised beta probability density function proposed by Ghysels et al. (2004, 2007):

$$
b\left(k ; \theta_{1}, \theta_{2}=\frac{\left[x_{k}^{\theta_{1}-1}\left(1-x_{k}\right)^{\theta_{2}-1}\right.}{\sum x_{k}^{\theta_{1}-1}}-\left(1-x_{k}\right)^{\theta_{2}-1}\right.
$$

where $x_{k}=\frac{k}{(K+1)}$. For robustness purposes, the analysis makes use of a different weighting scheme, which uses Almon lag polynomials of order $P$, specified as:

$$
\beta \mathrm{b}\left(k ; \theta_{0} \ldots, \theta_{p}\right)=\sum_{p=0}^{P} \theta_{p} k^{P}
$$

Finally, across both specifications, the analysis uses unrestricted MIDAS polynomials (U-MIDAS), i.e. without imposing any constraints. Such an unconstrainted MIDAS modelling is substantially useful when the number of high-frequency data linked to low-frequency observations) is small (Foroni et al., 2015).

\section{DATA}

Azzimonti $(2014,2018)$ constructs a PCI by using a semantic search approach to measure the frequency of newspaper coverage of articles reporting political disagreement about government policy issues, both within and between national parties, normalized by the total number of news articles to average 100 in 1990. The semantic search for this benchmark index is performed in Factiva (provided by Dow Jones), a newspaper database containing digitalized copies of all major U.S. newspapers, such as the Washington Post, the New York Times, the Los Angeles Times, the Chicago Tribune, the Wall Street Journal, the Newsday, the Dallas Morning News, the Boston Globe, and the Tampa Bay Times. Specifically, Azzimonti $(2014,2018)$ counts the number of articles that discuss disagreement between political parties, branches of government, or political actors (e.g., candidates not yet in office, legislators, etc.) in a given month. The study searches for articles containing at least one keyword in the following two categories, namely political disagreement and government, and focuses on specific terms related to partisan conflict, such as 'divided party', 'partisan divisions', and 'divided Congress'. This search approach captures disagreements not only about economic policy (e.g., related to budgetary decisions, tax rates, deficit levels, welfare programs), but also about private-sector regulation (e.g., financial and immigration reform), national defense issues (e.g., wars, terrorism), and other dimensions that divide policymakers' views (e.g., same-sex marriage, gun control, and abortion rights). As argued by Azzimonti (2018), high levels of partisan conflict are interpreted as situations where agreement between the two parties is hard to reach. For our empirical analysis, the monthly partisan conflict data come from the Federal Reserve Bank of Philadelphia.

Data on oil prices are the West Texas Intermediate Spot Prices (WTI), which are measured in dollars per barrel and are average spot prices. Data are provided by the U.S. Energy Information Agency database (EIA). We also use the Brent oil prices (average spot prices), which are sourced from Datastream. Both oil prices are at the daily frequency. . Following the common practice of the EIA, nominal oil prices are transformed to real terms by dividing the nominal prices by the Consumer Price Index (CPI). CPI data are monthly frequency (end of month values) and obtained from Datastream. Finally, the COVID-19 data are taken as the number of incidences as well as the number of deaths. They are daily data and are obtained from Datastream. All data span the period January 21, 2020 to April 30, 2020. Table 1 provides certain descriptive statistics.

\section{EMPIRICAL ANALYSIS}

The MIDAS regression results are reported in Table 2. The estimation scheme has considered 1 through 7 lags (up to a week) in the estimation process, with the final results based on a 2-day lag. They clearly document that both COVID-19 measures, and both oil prices measures, exert a negative effect on the PCI. However, results related to the COVID-19 pandemic event suggest that the impact on the partisan conflict measure is higher when the pandemic variable is 
Table 2. MIDAS estimates (normalised beta probability density function)

\begin{tabular}{|c|c|c|c|c|c|}
\hline Model & a & b1 & b2 & $\rho$ & Adjusted-R2 \\
\hline \multirow[t]{2}{*}{ Model 1} & 0.109 & $-0.096^{* *}$ & $-1.092^{* * *}$ & $0.586^{* * *}$ & 0.45 \\
\hline & [0.18] & [0.03] & [0.00] & {$[0.00]$} & \\
\hline \multirow[t]{2}{*}{ Model 2} & 0.094 & $-0.078^{* *}$ & $-1.037^{* * *}$ & $0.573^{* * *}$ & 0.42 \\
\hline & {$[0.22]$} & [0.04] & [0.00] & [0.00] & \\
\hline \multirow[t]{2}{*}{ Model 3} & 0.081 & $-0.174^{* * *}$ & $-1.066^{* * *}$ & $0.514^{* * *}$ & 0.58 \\
\hline & {$[0.26]$} & [0.00] & [0.00] & [0.00] & \\
\hline \multirow[t]{2}{*}{ Model 4} & 0.078 & $-0.168^{* * *}$ & $-1.014^{* * *}$ & $0.482^{* * *}$ & 0.55 \\
\hline & [0.29] & [0.00] & [0.01] & [0.00] & \\
\hline
\end{tabular}

This table reports results from MIDAS regression. Four models are estimated. Model 1 includes COVID-19 measured as total incidences and WTI oil prices; Model 2 includes COVID-19 measured as total incidences and Brent oil prices; Model 3 includes COVID-19 measured as total deaths and WTI oil prices; and Model 4 includes COVID-19 measured as total deaths and Brent oil prices. Figures in brackets denote $p$-values. ${ }^{* * * *}: \mathrm{p} \leqslant 0.01 ; * * \mathrm{p} \leqslant 0.05$.

Table 3. MIDAS estimates (Almon polynomial lags)

\begin{tabular}{|c|c|c|c|c|c|}
\hline Model & a & b1 & b2 & $\rho$ & Adjusted- $\mathrm{R}^{2}$ \\
\hline \multirow[t]{2}{*}{ Model 1} & 0.095 & $-0.091^{* *}$ & $-1.076^{* * *}$ & $0.549^{* * *}$ & 0.43 \\
\hline & [0.21] & [0.03] & [0.00] & [0.00] & \\
\hline \multirow[t]{2}{*}{ Model 2} & 0.090 & $-0.072^{* *}$ & $-1.025^{* * *}$ & $0.534^{* * *}$ & 0.41 \\
\hline & [0.24] & [0.05] & [0.01] & [0.00] & \\
\hline \multirow[t]{2}{*}{ Model 3} & 0.073 & $-0.156^{* * *}$ & $-1.049^{* * *}$ & $0.502^{* * *}$ & 0.56 \\
\hline & [0.30] & {$[0.00]$} & [0.00] & [0.00] & \\
\hline \multirow[t]{2}{*}{ Model 4} & 0.066 & $-0.144^{* * *}$ & $-1.002^{* *}$ & $0.465^{* * *}$ & 0.52 \\
\hline & [0.37] & [0.00] & [0.02] & [0.00] & \\
\hline
\end{tabular}

This tables reports results from MIDAS regressions based on Almon polynomial lags. Four models are estimated. Model 1 includes COVID-19 measured as total incidences and WTI oil prices; Model 2 includes COVID-19 measured as total incidences and Brent oil prices; Model 2 includes COVID-19 measured as total deaths and WTI oil prices; and Model 4 includes COVID-19 measured as total deaths and Brent oil prices. Figures in brackets denote $p$-values. ${ }^{* * * *}: \mathrm{p} \leqslant 0.01 ; * * \mathrm{*} \leqslant 0.05$.

measured as total deaths. This may reflect the stronger effect of COVID-19 deaths on the psychology of the entries of the PCI. Deaths signify stronger messages to human beings than cases per se; this, in turn, tends to polarize internal political conflicts across various parts of the political system, associated either with the reasons these deaths could not be avoided, or with the type of policy responses the government has implemented. Table 3 provides robust findings based on an Almon polynomial specification scheme, where the number of lags was also based on 2 . The new results provide robust support to the baseline results in Table 2. Across all models, the MIDAS-based estimates provide substantially higher adjusted $\mathrm{R}^{2}$ in the case where the COVID-19 is measured as total deaths, implying that the model offers better forecasts when the PCI update COVID-19 information coming in as total deaths. In other words, the estimates better incorporate the information coming as total deaths, which clearly illustrates the severity of the pandemic event. This type of information makes opposite political parties to stronger recede their political differences and to unite against either the pandemic disaster event or the perverse conditions in the oil market.

\section{CONCLUSION}

The propagation of COVID-19 pandemic and the recent oil crisis that resulted in negative oil prices, imposes serious threats to the US financial system, the US real economy, and public health. These events have mitigated the high political polarization observed in the US. The analysis explored how the combination of the pandemic and oil price shocks drove the US Partisan conflict environment. The findings illustrated that the global COVID-19 incidences and deaths, as well as oil prices, had a significant negative impact on the US Polarization Conflict index. It is probably evident in the US political environment that the spread of COVID-19 can only be stopped by concerted collective actions. Nevertheless, the normalization of both stressful events may bring back the political polarization differences, with the usual negative repercussions to the economic and social life in the US. 


\section{REFERENCES}

Aloui, R., Gupta, R., \& Miller, S. M. (2016).

Uncertainty and crude oil returns. Energy Economics, 55, 92-100. https://doi.org/10.1016/j.eneco.2016.01.0 $\underline{12}$

Andreou, E., Ghysels, E., \& Kourtellos, A. (2010). Regression models with mixed sampling frequencies. Journal of Econometrics, 158(2), 246-261. https://do i.org/10.1016/j.jeconom.2010.01.004

Andreou, E., Ghysels, E., \& Kourtellos, A. (2013). Should macroeconomic forecasters use daily financial data and how? Journal of Business \& Economic Statistics, 31(2), 240-251. https://doi.org/10.1080/07 $\underline{350015.2013 .767199}$

Azzimonti, M. (2014). Partisan conflict. Working Paper, No. 19, Federal Reserve Bank of Philadelphia.

Azzimonti, M. (2018). Partisan conflict and private investment. Journal of Monetary Economics, 93, 114-131. https://doi.org/10.1016/i.jmoneco.2017.10.0 $\underline{07}$

Boxell, L., Gentzkow, M., \& Shapiro, J. (2017). Is the internet causing political polarization? Evidence from demographics. National Bureau of Economic Research. https://doi.org/10.3386/w23258

Foroni, C., Marcellino, M., \& Schumacher, C. (2015). Unrestricted mixed data sampling (MIDAS): MIDAS regressions with unrestricted lag polynomials. Journal of the Royal Statistical Society: Series A (Statistics in Society), 178(1), 57-82. https://doi.org/1 $\underline{0.1111 / \text { rssa. } 12043}$

Ghysels, E., Santa-Clara, P., \& Valkanov, R. (2004). The MIDAS touch: Mixed data sampling regression models [Discussion Paper]. University of North Carolina and UCLA.
Ghysels, E., Sinko, A., \& Valkanov, R. (2007). MIDAS regressions: Further results and new directions. Econometric Reviews, 26(1), 53-90. https://doi.org/1 $\underline{0.1080 / 07474930600972467}$

Gupta, R., Lau, C. K. M., Miller, S. M., \& Wohar, M. E. (2019). US fiscal policy and asset prices: The role of partisan conflict. International Review of Finance, 19(4), 851-862. https://doi.org/10.1111/irfi.12188

Jones, D. R. (2001). Party polarization and legislative gridlock. Political Research Quarterly, 54(1), 125-141. https://doi.org/10.2307/449211

Layman, G. C., Carsey, T. M., \& Horowitz, J. M. (2006). Party polarization in American politics: Characteristics, causes, and consequences. Annual Review of Political Science, 9(1), 83-110. https://doi.o rg/10.1146/annurev.polisci.9.070204.105138

McCarty, N. (2007). Chapter Nine. The Policy Effects of Political Polarization. In P. Pierson \& T. Skocpol (Eds.), The Transformation of American Politics (pp. 223-255). Princeton University Press. https://doi.org/ 10.1515/9781400837502-013

McCarty, N., Poole, K. T., \& Rosenthal, H. (2006). Polarized America: The Dance of Ideology and Unequal Riches. MIT Press.

McGrath, M. C. (2017). Economic behavior and the partisan perceptual screen. Quarterly Journal of Political Science, 11(4), 363-383. https://doi.org/10.1 $\underline{561 / 100.00015100}$

Uddin, G. S., Bekiros, S., \& Ahmed, A. (2018). The nexus between geopolitical uncertainty and crude oil markets: An entropy-based wavelet analysis. Physica A: Statistical Mechanics and Its Applications, 495, 30-39. https://doi.org/10.1016/j.physa.2017.12.025 